\title{
Pedagogia da criação musical hoje: partir da infância, passar pela adolescência e ir além*
}

\author{
The pedagogy of musical creation today: from early \\ childhood to adolescence and beyond
}

François Delalande ** delalande.fr@wanadoo.fr

Tradução:

Tamya Moreira*** tamya.moreira@gmail.com

\footnotetext{
* O texto é resultado de uma conferência e sua publicação original em francês consta na obra: GIACCO, Grazia; DIDIER, John; SPAMPINATO, Francesco (Dir.). Didactique de la création artistique: Approches et perspectives de recherche. Louvain, Belgique: EME éditions, 2017. p. 165-187. A presente tradução foi realizada por Tamya Moreira e contou com a participação do autor. <https://www.francois-delalande.fr/>

** Pesquisador do Groupe de Recherches Musicales (GRM) do Institut National de I"Audiovisuel (INA).

*** Doutoranda no Programa de Pós-Graduação em Música (PPGMUS) da Escola de Comunicações e Artes (ECA) da Universidade de São Paulo (USP), na linha de pesquisa Música e Educação: processos de criação, ensino e aprendizagem.
} 


\section{Resumo}

A criação musical, que há setenta anos estava restrita a músicos profissionais, é hoje acessível a amadores e crianças. Esta prática pode ser sua primeira experiência musical e a base de um processo educacional. $O$ estudo de estratégias composicionais mostra que no centro do processo criativo encontra-se uma "ideia musical". O que é uma "ideia musical"? Trata-se de uma singularidade sonora que atrai a atenção do músico e o incita a estendê-la. Para estender sua descoberta, ele a repete com variações. A ideia musical - que há um século era geralmente um tema ou um motivo - é, nos dias de hoje, geralmente uma sonoridade particular. No entanto, repetir e variar um som distinto é típico do comportamento de exploração sonora da primeira infância, algo conhecido como "reação circular". Assim, desde a infância, é possível encorajar um comportamento de exploração que se torna invenção, uma vez que seja intencional. Tal comportamento pode ser enriquecido pela dimensão simbólica e, posteriormente, pelo gosto pela construção. A criança percorre diferentes formas de jogo, como analisado por Piaget: o jogo sensório-motor, o jogo simbólico e o jogo baseado em regras. O papel do educador é, então, estimular e guiar este desenvolvimento espontâneo, e alguns equipamentos podem ajuda-lo. Por volta de nove ou dez anos de idade, o computador é uma ferramenta conveniente para a composição.

Palavras-chave: Infância; Música; Invenção.

\section{Abstract}

Musical creation, which 70 years ago was practiced only by professional musicians, is today accessible to amateurs and children. It can be their first musical experience, and the basis of an education. Study of compositional strategies shows that at the heart of the creative process is a "musical idea". What is a "musical idea"? It is an interesting sound which attracts the attention of the musician and makes him want to extend it. To extend the discovery, the composer repeats it with variations. The musical idea, which a century ago was usually a theme or motif, is today more commonly a particular sonority. Repeating a distinctive sound and varying it, however, is typical of the sound-exploration behavior of early childhood, known as "circular reaction". Thus, from childhood, it is possible to encourage exploratory behavior, which becomes invention once it is intentional. This behavior can be enriched by the dimension of symbols and afterward by a taste for creating. The child goes through the different forms of game-playing, as analyzed by Piaget: the sensorimotor game, the symbolic game, and the rule-based game. The role of the educator is then to stimulate and guide this spontaneous development. Certain equipment can help. After the age of about 9 or 10 , the computer is a suitable tool for composition.

Keywords: Childhood; Music; Invention 
Como introdução, eu gostaria de citar uma produção vocal de uma criança de três anos de idade que me parece exemplar por alguns motivos. Primeiro, porque se trata de uma produção musicalmente interessante e surpreendente. Segundo, pois demonstra uma atitude pedagógica notável por parte da educadora. O terceiro motivo, enfim, consiste em minha satisfação pela abertura que pude proporcionar aos educadores e educadoras que orientei. Tudo isso ficará claro no relato seguinte.

A cena se passa com um grupo de crianças de um escola de educação infantil em Arras, uma cidade no norte da França. Eu mantinha encontros mensais com educadores e educadoras, e nós havíamos equipado algumas salas com materiais de gravação de boa qualidade, com vistas a favorecer atividades de exploração e de criação musical. Uma das educadoras era particularmente pouco afeita a inovações - isso é um eufemismo - e desenvolvia trabalhos pouco criativos com as crianças. Um dia, porém, ela havia preparado o microfone - provavelmente para gravar uma história corriqueira - e uma menina se aproximou e começou a fazer estalos com a língua, como fazemos quando testamos o equipamento. Ao invés de interromper a criança, a educadora fez uma gravação, pensando que essa atividade "certamente agradaria ao François Delalande". O que me deixa realmente realizado é o fato de que não foi apenas para me agradar, pois tal atitude mostra que, ainda que distante de apreciar, a educadora reconheceu que ali havia uma exploração original por parte daquela criança. O que me interessa é que a educadora tenha sido capaz de intuir que se passava algo que poderia ser importante para a criança, mesmo sem ter clareza sobre sua relevância.

Em tal produção sonora, a menina começa fazendo estalos com a língua, o que não se desenvolve pela falta de variações possíveis para esse som. No entanto, em seguida ela muda, fazendo um " $\mathrm{m}$ " com a boca fechada, o que a permite fazer variações. Assim, ela passa de uma exploração a uma espécie de improvisação, mesmo que ela esteja sempre em uma atitude de exploração, visto que se mantém experimentando os sons que faz com a boca. Porém, para que continue interessante, ela é levada a fazer modificações na repetição. E isso é tudo, pois não há uma ideia de forma. Talvez haja uma forma que se mostre posteriormente, mas não existe a intenção de construí-la. Aqui, encontramo-nos em uma fase preliminar da invenção na qual a exploração se torna, de maneira despretensiosa, uma forma de improvisação.

Lembremos que isso se passou em meio a um grupo de crianças em uma sala de educação infantil. Escuta-se a gravação com dificuldade, pois há também amplificadores que produzem sons em alto volume na sala e as crianças ficam completamente fascinadas pelo resultado. Isso diz respeito ao efeito de tais dispositivos, o que desenvolverei adiante.

Há uma evolução de caráter melódico: no início, há sons repetidos regularmente em uma só altura, cerca de um som por segundo, depois a matéria sonora se transforma em pequenos glissandi e, por fim, chega a intervalos de duas notas. A progressão é, de fato, surpreendente, pois a produção começa muito tensa, visto que a menina está inquieta - é a primeira vez que ela escuta sua própria voz desta maneira, amplificada, vindo do fundo da sala - e, aos poucos, ela simplesmente relaxa. Assim, há uma passagem entre tensão e relaxamento, o que é um dos grandes propulsores da música, prin- 
cipalmente da música tonal. Não levo essa comparação adiante aqui, mas indico apenas que é possível observar, nesse caso, uma evolução de caráter expressivo.

Gostaria, então, de comentar essa produção de diferentes pontos de vista. O que vou insinuar, e mesmo desenvolver mais detalhadamente, é que existe uma relação entre as reações circulares do início da infância, mesmo no primeiro ano de vida, e o desenvolvimento de uma ideia musical.

\section{Das reações circulares à ideia musical}

Começo com uma reflexão sobre o que é ideia musical para, em seguida, observar como tudo se inicia na infância.

\section{A ideia musical no processo composicional}

A análise de processos composicionais é um dos meus temas de pesquisa. Realizei um estudo aprofundado com doze compositores trabalhando nas mesmas condições, com materiais e softwares semelhantes ${ }^{1}$. A instrução era para partir de um som e, com ele, compor uma obra de três ou quatro minutos. Em seguida, pedi que mostrassem seus esboços e fiz entrevistas, o que permitiu, na medida do possível, estabelecer um modelo do que se passa em um processo de criação musical, em composição. É preciso especificar que se tratava de compositores do GRM ou muito próximos ao grupo, logo, próximos à música eletroacústica. Não é certo que as estratégias composicionais seriam as mesmas para músicas completamente diferentes. Não posso afirmar que esse modelo seria generalizável. Dito isso, acredito que qualquer composição segue, ao menos um pouco, esta grade de análise.

Primeiramente, há o que chamo de níveis de decisão. Um primeiro nível de decisão é o propósito. Vou fazer uma música que ilustra, por exemplo, os quatro elementos: a terra, o fogo, a água e o ar. É algo verbalizável e que podemos explicar de maneira fácil, muito frequente em notas de programa: "Eu quis fazer uma música sobre um poema de Armand Gatti...". Essa parte verbalizável é o que chamo de propósito. Porém, para começar realmente a compor, é preciso dispor de um ponto de partida que seja da ordem do sonoro. Se vou compor sobre a terra, é necessário encontrar o som, as formas sonoras que possam ser relacionadas à terra, o que me permitirá começar a trabalhar. É isso que chamo de ideia musical, e isso sempre existiu. No passado, tratava-se principalmente de um tema. O compositor pensa: "Esse motivo é interessante, posso fazer algo partindo dele, desenvolvê-lo".

Por definição, a ideia musical é algo que encontramos no processo de criação, mesmo que apareça também na obra. Nós não a definiremos como um motivo que se encontra na obra, mas como um motivo que apareceu durante o trabalho composicional. O propósito e a ideia são os elementos de singularidade próprios a essa obra.

Há, além disso, os elementos de regularidade. Primeiro, as regras estilísticas que 
podem levar o compositor a pensar, por exemplo: "Não gosto de começar com crescendo, prefiro atacar de maneira brusca". São as escolhas pessoais, os hábitos do compositor. Ele pode ter preferência por mixagens bem claras, nas quais possamos diferenciar facilmente as vozes. São regularidades: tal compositor faz sempre de tal maneira. E há também as regras técnicas: as quintas paralelas a serem evitadas na música tonal ou os ruídos de fundo que evitamos na música eletroacústica.

\begin{tabular}{|c|c|c|}
\hline Propósito & Singularidade & - Descoberta fortuita \\
Ideia musical & & - Busca pela descoberta \\
\hline Gramática, regras de estilo & Regularidade & - Os rascunhos \\
Regras técnicas & & - A realização focada \\
\hline
\end{tabular}

Tab. 1 - À esquerda, os níveis de decisão e, à direita, o eixo descoberta/trabalho

Estes quatro níveis de decisão são uma primeira grade de análise dos processos composicionais. Uma segunda grade que permite descrever as estratégias de cada um concerne à maneira como surgem as ideias e como as exploramos. É isso que denomino o eixo descoberta-trabalho².

Uma primeira situação é a descoberta fortuita: "esse som é interessante! Eu o tomo, ele me incita a continuar o trabalho". Acontece que, às vezes, os compositores encontram ideias musicais por acaso, como através da manipulação inadequada de um software, por exemplo, que pode produzir um som surpreendente. Ao invés de pensar "Esse não era o som que eu queria", eles dizem "Não é o que eu procurava, mas, como o achei, vou explorá-lo". Uma outra maneira de encontrar é a busca pela descoberta. "Preciso de algo que evoque (ou se oponha) a isso... Pesquiso, procuro, e acabo por encontrar." E então, há o momento em que pensamos "Está bem, agora tenho tudo, basta fazer alguns rascunhos e começar a trabalhar". Quando entrevistamos compositores, frequentemente eles dizem: "Há um momento a partir do qual não procuro mais, tenho todos os elementos e um projeto". É o que denomino realização focada.

Atualmente, pode-se dizer que a análise de processos criativos está em voga e um campo de pesquisa fecundo se configura ${ }^{3}$. Tal interesse tem sua origem nos estudos de genética textual, uma disciplina inicialmente dedicada a obras literárias e agora também aplicada à genética de obras musicais.

\section{A ideia musical: tentativa de definição}

Para que possamos pensar a música na infância a partir do conceito de ideia musical, é preciso defini-lo. Trata-se de uma singularidade sonora que encontramos ao aca-

\footnotetext{
2 N. de T.: Os termos, no original, são: trouvaille-travail, trouvaille fortuite, recherche de la trouvaille e réalisation aveugle. 0 termo trouvaille pode ser traduzido ainda como ideia ou achado. Com vistas a não provocar ambiguidade com o termo ideia musical, também importante no presente texto, optou-se por descoberta.

3 É notável a realização de três grandes congressos sobre o assunto nos últimos anos, a saber: Lille, 2011; Montréal, $2013 ;$ Paris, 2015. Mais informações sobre este campo de pesquisa em Donin <http://tcpm2015.ircam.fr > (Acesso em: 12 set. 2017).
} 
so ou como resultado de uma pesquisa. Pensando na música do passado, pode ser um tema, um motivo rítmico etc. Sobretudo, o importante é que a encontremos, mesmo que em pensamento.

O conceito de ideia musical tem sua história. Muitos autores já falaram sobre ele, mas nem sempre de maneira precisa se compararmos à maioria dos termos do vocabulário empregado em análise. Ao observar pesquisas e discussões sobre o tema, chegamos a uma concepção moderna do termo (BUCI-GLUCKSMANN; LÉVINAS, 1993). A ideia musical é da ordem do sonoro, ao contrário do que apresentei anteriormente como propósito. É sonoro, mesmo que imaginado, e aparece durante o processo composicional, enquanto trabalhamos na preparação de uma obra. Em algum momento, o compositor reconhece uma ideia interessante, a qual ele explorará. Na literatura mais antiga, é corrente que a ideia apareça como um motivo que é desenvolvido na obra e o processo composicional não seja objeto de estudo. Atualmente, ao nos dedicarmos à análise dos processos de criação, tendemos a definir a ideia musical como algo que surge durante o trabalho composicional e que impele o compositor a prolongá-la, desenvolvê-la. As ideias podem coexistir, se cruzar, se sobrepor. Quando fazemos um organograma de uma estratégia de composição, observamos momentos nos quais o propósito conduz a busca de ideias e, em seguida, momentos de trabalho sobre as mesmas. Essas duas grades nos permitem fazer uma boa descrição de estratégias de composição.

Em suma, a ideia musical é uma singularidade sonora que aparece no decorrer do trabalho composicional e que incita seu próprio desenvolvimento. Na maioria dos casos, desenvolver significa repetir ao mesmo tempo em que se operam mudanças, o que, de maneira geral, chamamos de variação.

\section{As ideias musicais hoje: música de notas versus música de sons}

Gostaria de enfatizar que as ideias musicais atuais não são as mesmas do passado. O início do que chamo de "atual" pode ser situado por volta de 1950, quando se abandona a convenção segundo a qual a música de concerto se fazia necessariamente a partir de notas grafadas em partituras. A tecnologia usada para criar era a escrita e, desde o século XIII, compor implicava sempre em produzir partituras. Podemos chamar este período de "era tecnológica da nota", que já não condiz com o que começa a acontecer por volta de 1950. Precisamente, em 1948 nasce a música concreta, produzida com máquinas e cuja composição não se dá a partir de notas musicais. A novidade consistia simplesmente em não utilizar partituras nem instrumentos, e, sim, fazer uma música baseada em sons através da operação com máquinas. Talvez seja um pouco simplista como definição, porém, é preciso notar uma grande oposição entre músicas concebidas a partir de notas musicais e aquelas concebidas a partir de material sonoro. Situo essa revolução na década de 1950, não apenas em 1948, porque ela alcançou todos os setores musicais. Podemos dar como exemplo o rock (PETERSON, 1991). Em determinado momento, começou-se a fazer música em estúdios e já não era necessário que os músicos executassem as canções de uma só vez, passando a servir-se da nova possibilidade de gravar pequenos trechos e fazer montagens. Há, ainda, o exemplo da música 
barroca, cuja interpretação também sofreu influência na medida em que a sonoridade passou a ter valor equivalente ou ainda maior que outros aspectos interpretativos. Foi a partir de 1953 que a pesquisa pela sonoridade levou à criação de grupos que utilizam instrumentos de época. Não desenvolverei esse tema aqui, pois ele é vasto e profundo, mas afirmo que há uma ruptura clara em meados do século $\mathrm{XX}$, quando o som passa a ser o elemento central (DELALANDE, 2001). Não é difícil citar exemplos contemporâneos: uma peça de Michael Levinas, para flauta baixo com captação, Arsis-Thésis. Em certas passagens, ao invés de o instrumento ser tocado de maneira a produzir uma altura definida, escuta-se somente o ruído de ar da respiração do flautista, que inspira e respira, colorido pela ressonância da flauta.

O que se busca é uma certa qualidade do som e não as notas. Estamos longe de uma melodia. Insisto, assim, que a busca pela sonoridade abrange toda a segunda metade do século XX e início do século XXI.

Faremos uma observação análoga a respeito de todas as Sequenze de Luciano Berio, peças escritas para instrumento solista ou voz. Por exemplo, na Sequenza $V$, para trombone, pode-se escutar, em certos momentos, o trombonista cantando em seu instrumento, o qual é utilizado para colorir a voz. É uma singularidade sonora encontrada e explorada por repetição e variação. Este processo de invenção que consiste em produzir - mais ou menos ao acaso -, escolher e prolongar através de repetição e variação é fundamentalmente o mesmo que aquele observado quando uma criança de três anos, fascinada pelo " $\mathrm{m}$ ", o repete de boca fechada diante do microfone.

\section{Reações circulares e invenção}

Eu gostaria de destacar, então, essa aproximação histórica entre a produção de compositores e as explorações das crianças pequenas, o que nos permite tomar como musicais as explorações como aquela que apresentei no início deste texto. $E$, além de interpretá-las como verdadeiramente musicais, favorecer e desenvolver essas formas de exploração que, na verdade, sempre existiram. As crianças habitualmente produzem ruídos e, quando surge uma singularidade sonora que lhes detém a atenção, têm vontade de repeti-los. A partir de certa idade, a variação se soma à repetição e isso pode constituir o princípio dos processos de invenção musical na infância.

É admirável notar que, quando trata das reações circulares, Piaget frequentemente apresenta exemplos sonoros. As reações circulares já eram conhecidas, mas com os estudos de Piaget podemos observar seu desenvolvimento. Ele escreve: "Observa-se, em certos casos privilegiados, a tendência para repetir, por reações circulares, os sons descobertos por mero acaso" (PIAGET, 1978, p. 86). Temos, então, a descoberta fortuita: uma singularidade sonora que surge inesperadamente. "Lucienne, aos dois meses e doze dias de idade, depois de ter tossido, recomeça repetidas vezes por prazer e sorri" (Ibid.). Eu sugiro às mães e aos pais de filhos pequenos que instalem um microfone no berço. As pesquisas e a inventividade dos bebês são surpreendentes. Outro exemplo: "Aos dois meses e onze dias de idade, Laurent sopra, produzindo um vago ruído com a boca. Aos dois meses e vinte e seis dias de idade, reproduz os ruídos vocais que acom- 
panham habitualmente seu riso, mas sem rir e por simples interesse fonético" (Ibid.). Então, é a sua própria voz que lhe interessa. Para Piaget, esses são exemplos das reações primárias, relacionadas ao próprio corpo. Em seguida, aparecem as reações secundárias, produzidas com objetos do entorno. Aqui observamos um dispositivo, conceito que desenvolverei adiante.

Aos três meses e dez dias de idade, depois de Laurent ter aprendido a agarrar o que vê, ponho-lhe o cordão atado à argola diretamente na mão direita, enrolando-o simplesmente um pouco para que o agarre melhor. Durante um momento, nada se passa; mas, à primeira sacudida fortuita, causada pelos movimentos de sua mão, a reação foi instantânea: Laurent tem um sobressalto, ao ver e ouvir a argola, depois desfere violentos golpes no cordão só com a mão direita [...] A operação dura um bom quarto de hora, durante o qual Laurent ri às gargalhadas (lbid., p. 159).

Temos uma típica reação circular: som produzido por acaso - neste exemplo, um acaso preparado pelo pai - que incita a criança a recomeçar, porque foi surpreendente. É uma reação de novidade.

Por volta de sete meses de idade, os bebês não apenas repetem com exatidão, mas também buscam fazer variações, o que torna as observações ainda mais intrigantes. Eles repetem e modificam, e este momento da mudança é o que muito nos interessa.

Insisto, então, na possibilidade de encontrar maneiras de promover a evolução destas explorações, e isso nos leva ao domínio da didática. O objetivo é favorecer o desenvolvimento de tal comportamento, que tem como característica a espontaneidade. Até este momento, o educador ou a educadora não tem necessidade de intervir, basta que esteja atento, valorize e destaque as descobertas das crianças. É por isso que fico contente com o exemplo do início do texto, pois consegui levar uma educadora que não estava totalmente preparada a estar atenta à produção inesperada de uma criança e reconhecer que algo interessante acontecia e, por isso, deveria ser gravado. Que ela tenha percebido que algo importante se passava, mesmo sem compreender totalmente, é um sucesso pedagógico. Na verdade, o desenrolar de situações que não foram previstas e desejadas pelo educador é frequente, estamos sempre lidando com este cenário. $O$ educador deve estar pronto para guiar e fazer com que as crianças progridam em processos que são originalmente espontâneos, pois, se permanecemos no estágio da espontaneidade, não caminhamos e as crianças logo se detêm. Elas fazem seus pequenos ruídos aos quatro meses de idade e talvez os continuem fazendo aos três anos, mas as explorações passam a ser menos prováveis. Acredito na importância de conduzir as pesquisas das crianças, de maneira a enriquecê-las para que se tornem formas de invenção e composição.

\section{Guiar sem impor: os dispositivos}

Como fazer com que a invenção progrida? A particularidade da educação artística em geral é que ela consiste em colocar as crianças (e também os adultos) em situação 
de pesquisa. Não compete àquele que guia uma atividade criativa dizer como devem ser os resultados. Um pensamento condizente com este papel seria: “É necessário que eu crie uma situação favorável para que ele - o aluno - encontre algo". Assim, o educador também se encontra em uma situação de pesquisa. A criação é uma pesquisa e não é possível saber os resultados de antemão. Podemos apenas fazer com que as crianças produzam algo que não sabemos exatamente o que será, pois elas farão suas escolhas durante o processo, enquanto produzem.

O conceito de dispositivo, que já evocamos duas vezes aqui, é muito útil. O primeiro exemplo é o microfone da exploração apresentada no início do texto. A professora o deixou disponível na sala com amplificação e qual foi o resultado? A admiração da menina que, ao fazer ruídos com a língua, descobriu, com surpresa, uma novidade sonora. O que nos leva novamente à terminologia das reações circulares, pois houve uma reação de novidade. Se ela fizesse os estalos com a língua em casa, em uma situação acústica corriqueira, ela pararia rapidamente. No entanto, nessa ocasião havia um microfone criando um som não esperado. Ao mesmo tempo em que ela o escuta saindo de sua boca, também o escuta vir de uma fonte afastada. Assim, ela está em uma situação de recepção e de produção. Ela escuta sua produção com uma certa distância, como um pintor que recua alguns passos para observar sua tela, então produção e recepção são concomitantes. Por fim, lembremos que as crianças escutam muito bem. Parece-nos evidente que, se o microfone não estivesse disponível, o som não seria daquela forma.

É então que o educador também precisa ser criativo, pois lhe cabe inventar dispositivos. Vimos outro exemplo de dispositivo em Piaget, que enrolou um fio na mão de seu filho para que, puxando-o, ele pudesse agitar o chocalho. Ele não tinha certeza do que aconteceria, mas apostou que algo aconteceria. Estamos sempre nessa situação: sabendo que algo vai se passar, mas sem saber previamente o resultado, pois isso dependerá da ação da criança. Aqui insistirei um pouco mais... Há situações nas quais, para que o desenvolvimento infantil se passe de maneira adequada, basta que a criança esteja em um ambiente favorável. Por exemplo, falar e andar não são habilidades que ensinamos, e sim atividades espontâneas quando há um ambiente que estimula o seu desenvolvimento. Estamos, na verdade, em uma situação análoga. É muito importante que, quando uma criança brinca com ruídos (como, no caso apresentado, estalos com a língua), alguém em seu entorno demonstre interesse, e este é o papel do educador. É importante que ele se interesse e que, em seguida, ele se faça entender. Para isso, frequentemente, um olhar interessado é suficiente. Há maneiras de criar reforços positivos como resposta às atividades espontâneas dos bebês, condutas de aprovação por parte dos educadores, e uma delas é simplesmente olhar. Estamos diante de vinte crianças e percebemos que algo que uma delas faz pode ir além, pode ser desenvolvido. Se a educadora dirige seu olhar para essa criança, as demais tendem a seguir essa direção, escutam o que está sendo produzido. Isso também estimula a criança que está na situação de produção, sobretudo se a educadora é querida pela turma. Esse tipo de interação é central. Trabalhei bastante com uma educadora, Monique Frapat, que me detalhava a organização de seu trabalho antes da aula. Durante a sessão com as crianças, ela não dizia nenhuma palavra, mas tudo se passava como previsto porque ela agia por pequenas e delicadas intervenções, como o deslocamento de algum objeto ou o direcionamento 
do olhar. São maneiras extremamente discretas de conduzir por reforços positivos.

$\mathrm{Na}$ formação de educadores, é preciso desenvolver a capacidade de observar o que as crianças fazem e de mostrar aprovação discretamente, e não dizer-lhes de maneira direta o que fazer. Dito isso, não sejamos extremistas. Podem existir situações nas quais é útil fazer o que Monique chama de retomada 4 . Isso consiste em intervir claramente dizendo: "Será que você não poderia também...", aprovando o que foi feito e sugerindo maneiras de ir além, mas sem determinar o resultado, incitando a criança a fazer ainda melhor.

Apresentarei, agora, exemplos variados de dispositivos empregados em creches com crianças pequenas. Começamos com um relato de um trabalho de pesquisa desenvolvido no norte da Itália (DELALANDE, 2015). O primeiro ano consistiu em observar as explorações individuais, quando as crianças estavam sozinhas. Essa situação, em meio escolar, não é recorrente. Como nas creches as crianças nunca ficam sozinhas, fizemos com que, uma a uma, entrassem em uma sala. A educadora explicava que ali se encontraria uma bela surpresa, e a criança descobria um instrumento musical: uma cítara ou um par de címbalos. Se tudo se passasse bem, a criança teria vontade de fazer sons com estes objetos. Nós deixamos à disposição outros materiais, como uma colher de metal e outra de madeira, mas as crianças também usaram os próprios dedos. Assim, elas se encontravam em uma situação de exploração. O procedimento padrão era o seguinte: assim que a criança começava, a educadora dizia "Já volto, vou buscar um lenço". Ela saía e deixava a criança sozinha o máximo de tempo possível, enquanto durasse a exploração. Isso variava, em média, entre cinco e sete minutos. Então, durante este tempo, a criança se encontrava sozinha diante de um instrumento a explorar, um dispositivo. Destaco um dado interessante: um terço das crianças não começou a exploração em presença da educadora, mas apenas depois de sua saída. Para a formação da educadora, esta é uma verdadeira aula sobre humildade. Felizmente, houve também casos contrários, nos quais a criança só se envolvia com a exploração se acompanhada da educadora. De qualquer maneira, a quantidade de crianças que só se manifestaram quando sozinhas é expressiva. Estas crianças também paravam logo que a educadora retornava, o que nos faz pensar que a exploração era uma situação realmente privada.

Nós também estudamos os efeitos de um dispositivo um pouco mais complexo: a cítara com microfones e amplificada. O resultado deste dispositivo foi que a ressonância foi mais perceptível e mais longa. Assim, os gestos ficaram mais lentos, interrompidos durante a ressonância. Isso nos deu uma produção artificial de gestos lentos.

Ao longo do segundo ano de pesquisa, escolhemos crianças que não haviam produzido sons na primeira etapa de experimentos e procuramos dispositivos que pudessem desinibi-las. Neste caso, colocamos duas crianças em um espaço organizado com instrumentos dispostos em semicírculo. Nossa hipótese era de que, assim, haveria alguma espécie de emulação.

As duas crianças entram na sala. São crianças consideradas "tímidas", pois não ha$4 \quad$ No original, relance. Neste caso, a educadora trata de uma intervenção estimulante em um processo que já se desenvolve, de maneira
a incentivar a prosseguir, a injetar energia na produção. 
viam feito nada diante de um instrumento ou outro objeto para exploração sonora. As imitações começam logo, eles desenvolvem um jogo em dupla que dura bastante tempo. Começam pelo mesmo instrumento/objeto e passam a imitar as formas sonoras. Primeiro, trata-se do espaço, pois elas se seguem passando de um instrumento a outro. Depois, as imitações passam ao âmbito sonoro. Uma criança produz uma forma sonora em um instrumento e esta é imitada vocalmente. A imitação já não se dá pelo uso do mesmo instrumento, e sim pela reprodução de formas sonoras. Então, partimos de algo muito concreto, como tocar o mesmo instrumento, passando em seguida a uma imitação rítmica e, por fim, a imitações ainda mais abstratas. Destaco que dispositivos diferentes favorecem condutas também diferentes. As explorações individuais podem ir longe, demorando, em média, entre cinco e sete minutos com variações. Não é o mesmo caso quando as crianças exploram o espaço em dupla. Elas variam bastante, mas o que está em desenvolvimento é a interação a dois, extremamente importante em música. De fato, desenvolvemos condutas fundamentalmente musicais, como a imitação, um procedimento de considerável importância na história da música. Imitamo-nos, cantamos e tocamos em cânone, como as duplas de crianças que exploram os instrumentos, enquanto as produções solitárias desenvolvem outros aspectos, como a escuta atenta. Cada dispositivo favorece condutas diferentes. É preciso procurar astutamente os dispositivos adequados para estimular o que queremos.

\section{E depois? As etapas de um enriquecimento da criação musical}

Até aqui, evocamos exemplos de exploração de crianças pequenas. Agora eu gostaria de avançar e mostrar como podemos chegar a uma atividade de composição. As reações circulares se desenvolvem enquanto o chamado período sensório-motor, que existe espontaneamente, é favorecido. E aqui insisto no fato de que isso não se ensina. A exploração é algo que as crianças fazem mesmo quando não há adultos. Ela vai mais ou menos longe de acordo com o contexto, o ambiente material - os dispositivos - e humano - as relações com os adultos que a encorajam, estimulam e aprovam. E depois, o que acontece?

\section{O simbolismo}

Após o período sensório-motor, desenvolve-se um período simbólico. As crianças fazem sons frequentemente, mas agora os sons passam a representar algo. Todos conhecem esse exemplo: a criança pega um objeto nas mãos, o faz voar e temos um avião. A idade propícia, neste caso, é cerca de quatro anos, mas isso se inicia muito antes. Por volta de dois anos de idade já existem formas de simbolização através do som, mas ainda são difíceis de estudar. Há um exemplo pessoal do qual me lembro muito bem: eu preparava um artigo e minha filha, com um ano e seis meses de idade, fez uma porta soar e disse "bebê". Ela conhecia apenas algumas palavras e este evento me deixou contente, pois correspondia ao que eu estudava. Vi como uma criança de um ano e seis meses é capaz de interpretar um som como evocação de algo. 
Tratarei aqui do simbolismo por volta de quatro anos de idade para, em seguida, descrever como as crianças começam a dar forma às suas produções. Disso, poderemos tirar conclusões sobre a relação entre jogo e música.

Um grupo de crianças de quatro anos, em uma aula de Monique Frapat, inventou uma história na qual o personagem vai ao mar e passa por uma tempestade. São crianças de Paris, o que significa que não têm familiaridade com o mar ou com grandes tempestades. Como elas a representam? Para elas, pensar em uma tempestade é algo um tanto abstrato. De uma maneira geral, para essas crianças, uma tempestade é algo muito forte, barulhento e cheio de grandes movimentos.

Não se trata de realismo acústico, como sonoplastia em cinema (ainda que, no cinema, a sonoplastia nem sempre se restrinja ao realismo). Não é, de fato, uma imitação fiel dos sons de uma tempestade o que se produz, pois isso não lhes é habitual. Elas não escutam tempestades, mas as associam a algo que dá medo, que é enorme, que produz grandes ondas. A partir dessas ideias, elas produzem formas sonoras que simbolizam a tempestade sem, de fato, imitá-la diretamente nas suas feições acústicas.

\section{Por volta de cinco e seis anos de idade: organizar a forma}

Observando as produções de crianças entre cinco e seis anos, podemos notar algo novo e muito interessante: nesta idade, elas são capazes de construir. $E$, a capacidade de construir se deve, simplesmente, à capacidade de antecipar. A menina de três anos que explora sua voz ao microfone vive a experiência no presente. Certamente existe uma evolução, mas ela não é intencional, planejada. Por outro lado, uma criança de cinco ou seis anos pode pensar, por exemplo: "Bom, eu fiz isso e ficou bom, então vou continuar e vou concluir assim". A ideia de finalizar - preparar deliberadamente um fim para a improvisação - é típica aos quatro anos em meios muito favoráveis, porém, em geral, é sobretudo por volta de cinco ou seis anos que as crianças demonstram a consciência da forma. Isso se deve à habilidade de antecipação e a outras razões. Dois exemplos ilustrarão essa conquista: uma menina de seis anos está começando sua exploração da cítara. Ela busca inicialmente os sons, como descrevemos no início do texto, a descoberta. Há um momento no qual ela encontra um material interessante e pensa: "Vou fazer algo com isso". Porém, por acaso, ela produz um choque e, a partir de então, ela passa a explorar duas ideias: um glissando pelas cordas da cítara e o choque que, depois de um crescendo, marca uma finalização. É tipicamente uma construção, uma forma, e isso é favorecido por um dispositivo: o gravador. A situação de gravação, aqui, faz a menina imaginar uma obra, um objeto determinado com começo, meio e fim. As crianças de três anos não se preocupam se estão sendo gravadas, isso não as influencia. É interessante, então, fazer com que as crianças que já demonstram consciência formal escutem novamente o que gravaram, pensando suas improvisações como produtos.

Uma outra criança de seis anos de idade faz uma improvisação vocal ao microfone. Ela produz algo de original e, logo em seguida, expressa uma crítica positiva: "Isso que fiz é bonito". Essa frase é muito significativa, pois o menino produziu algo ao acaso e apreciou. Quando há continuação, variações, desenvolvimento, é porque encontramos 
um certa beleza, um certo prazer.

Essas observações nos conduzem a uma conclusão essencial. Primeiro, descrevemos uma etapa sensório-motora, seguida da observação de uma etapa de forte desenvolvimento simbólico por volta dos quatro anos - o exemplo da tempestade -, quando as crianças representam com sons. Enfim, um pouco mais tarde, elas são capazes de organizar e dar formas às suas construções.

A capacidade de organizar uma forma está ligada a vários motivos. O primeiro, do qual já falamos, é o fato de que as crianças passam a ter a capacidade de antecipar. Eles podem projetar-se no futuro e pensar: "Encontrei algo interessante, então vou fazer evoluir e conduzirei ao fim". O segundo motivo é a comunicação com as demais pessoas através da música, o que denomino como componente retórico da forma. Por exemplo: quando há gravação, elas escutam novamente o que fizeram, o que incita uma atitude de desenvolvimento e finalização. Neste sentido, poderíamos evocar também um exemplo mais próximo à etnomusicologia. Um pastor que canta enquanto pastoreia suas ovelhas na montanha não tem motivo para se preocupar em finalizar sua improvisação. No entanto, se o mesmo músico canta ou toca para outras pessoas em uma cerimônia de casamento, ele vai pensar de maneira formal. $O$ fato de comunicar incita a construir.

A organização formal observada nas produções das crianças de cinco e seis anos explica-se, sobretudo, pois esta é uma época de intenso desenvolvimento do jogo de regras. Isso não se dá apenas com os sons, mas é frequente em atividades sensório-motoras, por exemplo, quando as crianças inventam brincadeiras repentinas e desafiadoras, como descer escadas em apenas uma perna. $O$ jogo da amarelinha é um grande exemplo desse período característico de desenvolvimento. Em música, isso existe em forma de brincadeiras cantadas, como as fórmulas de escolha, quando fazemos uma frase entrar em uma estrutura melódico-rítmica. É uma forma de jogo de encaixe, como aqueles que consistem em inserir triângulos dentro de triângulos e círculos dentro de círculos. Essas ideias estão na base da música ocidental polifônica, como nas formas de cânone e fuga, por exemplo.

\section{Fazer música: um jogo piagetiano}

Descrever as etapas dos diferentes jogos do desenvolvimento infantil parece-nos útil pois, em um âmbito antropológico, a proposição de uma definição geral de música é um problema recorrente. Dizemos que todos os povos fazem música, contudo, essas produções diferem consideravelmente. A discrepância chega a tal ponto que Blacking, autor do livro How musical is man? (BLACKING, 1973), constata que não existiria justificativa para nomear todas as produções com o mesmo termo: música. Esta é, então, a questão central: o que há de comum? Neste ponto, conseguimos avançar consideravelmente na medida em que substituímos a busca pelas características comuns entre as músicas tomadas como objetos, por uma busca pelo que há de generalizado na própria atividade de fazer música. Trata-se de observar as condutas de produção musical, o que nos permite considerar o momento no qual fazemos música. 
Isso acontece, primeiramente, quando nos interessamos pelo som em si mesmo e o dominamos, trabalhamos com ele - ao contrário, por exemplo, do som da voz falada. Quando falamos, não é essencial que a voz seja bela ou não, pois nosso interesse concentra-se na mensagem. Isso é diferente do que acontece ao tocarmos um instrumento, pois é uma situação de domínio e extrema atenção ao som, como quando um flautista regula seus gestos para produzir determinada sonoridade com a flauta. Há um grande controle sensório-motor nessa produção, que não está restrito à escuta, mas também diz respeito ao toque, à sensação de pressão etc., engendrando um circuito de ação e reação.

Em seguida, há uma forma de simbolismo. Esse tema gera muitos debates, pois há os formalistas, que defendem que a música não significa nada além dela mesma. Isso é verdade, mas em algum nível outras coisas se exprimem. Há simbolismo em tudo, mesmo em relação às mais distintas classificações de instrumentos. Todas as culturas envolvem alguma forma de simbolismo nas produções que denominamos musicais.

Por fim, essas produções têm regras, organização. $O$ fato de que os jogos sensório-motor, simbólico e de regras se desenvolvam durante a infância favorece muito nosso trabalho em educação musical. Contribuir para o desenvolvimento de tais jogos, propiciando situações nas quais essas condutas possam se manifestar e se aprimorar, é o suficiente para promover um perfeito desabrochar de músicos. Basta refletirmos sobre a constatação de que os jogos observados na infância estão intimamente ligados às condutas que definem a atividade musical de uma maneira geral (DELALANDE, 1984).

\section{Enfim, chega o computador}

Vejamos agora o que acontece com a chegada do computador. Nós mudamos de idade e também de tecnologia. Sinteticamente, vamos tratar da introdução de tecnologia digital.

Já há algumas décadas, em meados dos anos 1980, com o início da popularização de computadores domésticos, começamos a usar sistemas híbridos para manipular sintetizadores. Isso também chegou rapidamente às escolas. O progresso tecnológico é tanto que, atualmente, fazer música com computadores que produzem sons por si mesmos é algo corriqueiro.

Um belo exemplo é o trabalho de Stefano Luca, sound designer e pesquisador italiano. Por muito tempo, fazer música com computadores era uma prática presente nos anos finais do ensino fundamental de muitas escolas europeias, mas não nos anos iniciais. Nós criávamos música vocal ou, por exemplo, com potes de iogurte e outros objetos cotidianos. Frequentemente esses trabalhos têm resultados muito bonitos, podem levar a criações infantis muito interessantes. No entanto, por vezes, esse trabalho se torna muito difícil para o educador, pois as crianças crescem e, já por volta dos nove ou dez anos de idade, suas concepções musicais, sobretudo quando ligadas à música popular industrializada, passam a se afastar desse tipo de atividade. É necessário, neste caso, procurar as ferramentas, técnicas e tecnologias mais atraentes e valorizadas pelas crianças maiores. $\mathrm{E}$ uma tecnologia muito interessante é, evidentemente, o computador. 
Stefano Luca desenvolveu um trabalho de composição coletiva com crianças na associação Tempo Reale, na região italiana de Florença. As crianças de algumas turmas participaram de um projeto de composição com o tema "os quatro elementos". Elas trabalharam com potes de iogurte, papel, entre outros objetos cotidianos, mas com uma particularidade: seus sons estavam sendo captados por microfone. Uma das crianças, aliás, era responsável pela função de microfonista. Em um trabalho como este, é evidente que a situação de gravação é determinante. Todos os sons captados eram enviados ao computador. O tratamento se fez em tempo real - o que significa que, logo que captados pelo microfone, os sons sofriam alterações, espacialização etc. - e posteriormente. Assim, foi possível envolver várias crianças no processo de composição em ateliê, produzindo um concerto ao fim do trabalho ${ }^{5}$.

No concerto, reuniram-se todas as turmas, bem como suas famílias e representantes políticos da região, e todos puderam observar como, valendo-se de meios um pouco mais sofisticados para tratar sons gravados, pode-se realizar um trabalho que vai além do habitual. Este exemplo é muito importante para mim, pois acompanhei o desenvolvimento da informática nos anos finais do ensino fundamental e esperava pelo dia em que ela chegaria também aos anos iniciais.

Ensinar uma criança nesta faixa etária a utilizar programas de tratamento, montagem e mixagem sonora, para que ela seja capaz de compor autonomamente uma pequena peça, pode ser muito simples. A pequena Silvia, aos nove anos de idade, depois de orientada a fazer manipulações sonoras simples, foi capaz de compor pequenas peças por si mesma, em sua casa, entre as quais algumas são verdadeiramente notáveis. Em uma delas, Silvia utiliza a gravação de uma gota d'água, que ela manipula tornando mais lenta ou acelerando, de maneira a criar expectativa, superposição e até um stretto final. Ela conseguiu fazer uma verdadeira composição. Da mesma maneira, ela criou uma pequena peça a partir de um poema conhecido, o qual ela mesma lê com diferentes entonações. Em seguida, ela tratou e superpôs as frases gravadas, obtendo uma grande paleta expressiva e uma polifonia muito criativa ${ }^{6}$. São exemplos de que, certamente, uma criança que tem por volta de dez anos de idade pode dominar técnicas de composição ao computador.

\section{Duas notas para concluir}

Mais que uma conclusão, termino com uma espécie de post-scriptum na forma de dois comentários:

\section{Criação na escola e criação amadora}

O primeiro comentário consiste em notar que, assim que as crianças dominam um

\footnotetext{
5 É possivel escutar essa peça, nomeada Gamelan 01, no site do GRM: <http://www.inagrm.com/search/node/gamelan\%2001>. 6 É possivel escutar algumas composições da pequena Silvia no site do GRM Creamus: <http://creamus.inagrm.com/co/HP_creamus_ site.html>
} 
pouco de informática, elas se aproximam de um universo muito desenvolvido, a saber: o de compositores amadores. No âmbito social, algo de muito interessante se passou: criar músicas no computador pessoal, de maneira amadora, tornou-se algo relativamente banal. Para afirmar isso, baseio-me em um estudo desenvolvido em 2002 por Pouts-Lajus et al., o qual mostra que havia, naquele momento, um milhão de compositores amadores criando músicas em seus computadores pessoais, apenas na França. Esta é uma quantidade enorme, socialmente muito significativa. No âmbito qualitativo, a pesquisa mostra que se trata, sobretudo, de pessoas que têm empregos que garantem suas rendas e que compõem músicas por prazer, em seu tempo livre. Neste aspecto, vejo como muito importante a aproximação entre o fazer musical escolar e a realidade de uma sociedade com número expressivo de compositores amadores. Pensando na força da verticalização das funções sociais e musicais, vemos que a figura do compositor ganha estatuto de celebridade no século XIX e, com o desenvolvimento de uma indústria cultural onde existem produtores e consumidores, isso se torna ainda mais forte no século XX. Tem-se uma organização verticalizada, onde cabe a poucos o direito à produção e, aos demais, sobra a mera função de aplaudir. Essa organização entra em conflito com o que vemos agora, o que eu chamaria de sociedade horizontal. Trata-se de pessoas que não têm pretensão de vender milhões de discos nem de se tornarem celebridades, mas que fazem músicas em casa e gostariam de compartilhá-las com seu entorno. Por vezes elas fazem discos, mas com tiragens pequenas e, sobretudo, fazem suas produções circularem via internet. Por vezes fazem concertos, mas em lugares pequenos e, sobretudo, para pessoas que também fazem suas músicas de maneira amadora. Socialmente, é uma organização que difere da verticalização industrial, promovendo experiências psicológicas e sociais novas aos indivíduos envolvidos. Temos uma outra sociedade musical, distante daquela que se baseia no marketing, e da qual a escola pode ser a geradora. A esta consideração dedico o primeiro post-scriptum.

\section{Aproximação com as artes plásticas}

O segundo post-scriptum concerne à relação entre música e arte contemporânea. Sabemos que os movimentos de pintura do início do século XX são intimamente ligados ao que chamamos hoje de arte infantil. Anteriormente, as crianças já faziam suas garatujas, mas não as levávamos a sério, nunca dizíamos que se tratava de arte. Isso mudou na medida em que artistas como Matisse, Klee, Kandinsky começaram a se interessar pelo que chamavam de "arte primitiva", proveniente de outras culturas, e pelo que as crianças faziam. E então o conceito de arte infantil é levado em consideração, principalmente no pós-guerra. Lembremos dos trabalhos de Arno Stern, de ateliês de criação com murais, e mesmo que, em 1951, o tema é tratado em colóquio específico pela Unesco (ZIEGFELD, 1954). Vimos uma transferência de ideias do campo da arte para o campo da educação, o que também ocorreu com a música. O advento da música concreta, em 1948, tem como resultado nossa capacidade de, atualmente, considerar como musical a exploração sonora que uma pequena menina de três anos de idade faz diante de um microfone. A partir do momento em que os músicos se dedicaram à ta- 
refa de fazer música com ruídos, com sons, torna-se possível escutar as produções das crianças de uma nova maneira, encontrando aspectos musicais.

$\mathrm{E}$, atualmente, o que se passa no campo da arte contemporânea? Não tenho como dizer exatamente aqui, mas termino com um exemplo de como as crianças são capazes de fazer, em aula, atividades muito próximas do que os artistas contemporâneos produzem. Relato algo que se passou na aula de uma educadora que já citei aqui, Monique Frapat, algo que poderíamos chamar de performance ou happening. A educadora, com a ajuda de um pai, teve a ideia de encher balões de gás hélio para suscitar um processo criativo com as crianças. Cada aluno se apropriou de um balão, ao qual deu nome e decorou à sua maneira, até o dia em que todos acordaram em soltar os balões. Organizou-se um evento, todos foram ao pátio e deixaram seus balões, dos quais cuidaram durante semanas, voarem. Evidentemente, houve choro e alguma tristeza, mas esse evento propiciou uma atividade de invenção considerável. Várias histórias foram inventadas sobre o futuro dos balões: houve um que foi à lua, outro foi à China etc. Essas histórias desdobraram-se em atividades como cozinhar arroz e estudar demais aspectos da cultura chinesa, o que possibilitou uma formação geral e, acredito, uma condução artística. Na organização desta performance, foi criada uma circunstância artística que possibilitou uma grande atividade criativa. Monique Frapat instalou, em um canto da sala, um espaço para gravar mensagens para os balões que partiram. Uma grande variedade de criações foi gravada, incluindo composições musicais, estimuladas por uma situação artificial, inventada pela educadora. Este é um grande exemplo de dispositivo: uma maneira de provocar, de estimular a criação, lançando-se em uma situação da qual não sabemos o resultado de antemão.

\section{Referências}

BLACKING, J. How musical is man? Seattle, London: University of Washington Press, 1973.

BUCI-GLUCKSMANN, C.; LÉVINAS, M. (Dir.). L'idée Musicale. Saint-Denis: Presses Universitaires de Vincennes, 1993.

DELALANDE, F. La musique est un jeu d'enfant. Paris: Ina/Buchet-Chastel, 1984

DELALANDE, F. Éléments d'analyse de la stratégie de composition. In: Actes du colloque: structures musicales et assistance informatique 1-4 juin 1988. Marseille: MIM, CNR, 1989. p. 51-65.

DELALANDE, F. Toward an Analysis of Compositional Strategies. Circuit, Montréal, v. 17, n.1, p.11-26, 2007.

DELALANDE, F. Le son des musiques, entre technologie et esthétique, Paris: Ina/Buchet-Chastel, 2001. 
DELALANDE, F. et al. Naissance de la musique, les explorations sonores de la première enfance. Rennes: PUR, Ina-éditions, 2015.

DONIN, N.; TRAUBE, C. (Dir.): Tracking the creative process in music. Musicæ Scientiæ, v. 20, n. 3, numéro special, Septembre 2016.

PETERSON, R. A. Mais pourquoi donc en 1955? Comment expliquer la naissance du rock. In: MIGNON, P. et HENNION, A. (Ed), Rock, de l'histoire au mythe. Paris: Anthropos, 1991.

PIAGET, Jean. O nascimento da inteligência na criança. Rio de Janeiro: LTC, 1978.

POUTS-LAJUS, S.; TIÉVANT, S.; JOY, J.; SEVIN, J.-C. Composer sur son ordinateur. Les pratiques musicales en amateur liées à l'informatique. Les travaux du DEP. Ministère de la Culture et de la Communication (France), 2002. Disponível em: <http://www2.culture.gouv.fr/culture/deps/2008/pdf/tdp_ordinat.pdf>

ZIEGFIELD, E. (Dir.). Art et éducation. Paris: Unesco, 1954. 